\title{
Pre-emptive competition as a selective pressure for early reproduction in the polychaete Nereis virens
}

\author{
C. Lewis ${ }^{1,2, *}$, P. J. W. Olive ${ }^{1}$, M. G. Bentley ${ }^{1}$ \\ ${ }^{1}$ Department of Marine Sciences and Coastal Management, University of Newcastle-upon-Tyne, Newcastle NE1 7RU, \\ United Kingdom
}

${ }^{2}$ Present address: International Ocean Institute-Southern Africa, Department of Biodiversity and Conservation Biology, University of the Western Cape, Private Bag X17, Bellville 7535, South Africa

\begin{abstract}
Reproduction in the semelparous polychaete Nereis virens occurs at a time of year when seawater temperatures are lower than the optimum temperatures for fertilization and larval development and at a time when seawater temperatures are rising. This study assesses the possible role of intra-specific competitive interactions between settling $N$. virens post-larvae as a selective pressure for 'early' reproduction. A series of laboratory competition experiments were conducted between 2 cohorts of $N$. virens post-larvae, under a range of environmental conditions. Significant pre-emptive competition between settling post-larvae was recorded at $15^{\circ} \mathrm{C}$, whereby a survival advantage was gained via prior residence with early larval settlers out-competing later arrivals. This competitive interaction was reduced at lower temperatures and no significant effect was measured at $5^{\circ} \mathrm{C}$. An increase in age difference between the 2 cohorts of post-larvae increased the competitive effect, whilst photoperiod regime and food availability had no significant effect on the outcome of these experiments. Intra-specific competition was greatest at the temperatures at which maximum fertilization and development are known to occur, but was reduced at the temperature range at which spawning occurs in the field. It is suggested, therefore, that pre-emptive competition between settling post-larvae forms a strong selective pressure for breeding early at a time of year when temperatures are below the optimum for fertilization and development.
\end{abstract}

KEY WORDS: Polychaeta $\cdot$ Pre-emptive competition $\cdot$ Nereis virens $\cdot$ Seasonal reproduction

\section{INTRODUCTION}

Highly synchronized seasonal reproduction is a widespread phenomenon among the majority of larger marine invertebrates (Babcock 1986, Giese \& Kanatani 1987, Babcock et al. 1994, Watson et al. 2000). Gamete release is synchronized within a population and confined to a period of time that can vary in duration from as little as just 1 or $2 \mathrm{~d}$ a year (Korringa 1957, Kubota 1981 ) to a more extended breeding season with a definite periodicity (Korringa 1957, Counihan et al. 2001). The period of gamete release has a fixed relationship with the solar cycle. As a consequence of this, in temperate, boreal and polar regions, offspring are exposed to a relatively small part of the range of environmental conditions that occur at the locality during the entire year.

The maintenance of precise physiological mechanisms to coordinate the timing of reproduction in relation to external environmental signals implies a degree of adaptive significance and selection of traits to maintain the observed periodicity. Such fitness benefits associated with seasonal reproduction are potentially diverse and are not well understood (see Olive 1992, Olive et al. 2000 and Lewis 2002 for discussion). Many of the traditional models that have been proposed to explain the fitness benefits of the precise timing of seasonal reproduction assume enhanced offspring survival, due to temperature constraints placed on fertilization and development at other times of the year (e.g. 
Orton 1920, Thorson 1950, Giese \& Kanatani 1987). A recent case study examining the seasonal influences on fertilization and early development in the semelparous polychaete Nereis virens Sars, however, has demonstrated that in this species reproduction occurs early, prior to the onset of optimal temperature conditions for fertilization and early development (Lewis 2002, Lewis et al. 2002). One possible explanation for such early reproduction might be that intra-specific competitive interactions operate at the post-settlement stage, whereby early arrivals gain a competitive advantage and so obtain a fitness benefit through enhanced post-larval survival.

Competition for space should be most evident among species that demonstrate territorial behaviour (Connell 1963, Bridges et al. 1996). Nereid polychaetes including Nereis virens are well known for their aggressive behaviour associated with defence of a burrow (Clark 1959, Evans 1973, Cram \& Evans 1980, Miron et al. 1992a). Behavioural studies have revealed fighting between adult $N$. virens when encountering other worms (Evans 1973, Miron et al. 1992a,b). This fighting behaviour includes everting the pharynx to display the jaws, biting and 'pushing' (contraction of the anterior end over the other individual without biting). Such aggressive behaviour appears to be more important in high-density conditions, though once installed in a burrow individuals make few interburrow encounters (Miron et al. 1992a). Increased population density in polychaetes is known to lead to modifications in the shape of the burrows (with less sub-surface connections), behavioural modifications in the time spent in various activities such as feeding and locomotion (Miron et al. 1991a,b), and reduced reproduction and juvenile recruitment (Kent \& Day 1983). Competition over a limited food supply is generally considered to be the primary cause of densitydependent effects among polychaetes (Bridges et al. 1996). Intra-specific competition and cannibalism have been described as highly important mechanisms involved in the regulation of adult populations and are considered a major source of mortality in $N$. virens (Kristensen 1984, Miron et al. 1992b).

Intra-specific competition is not just confined to adult Nereis virens populations. Juveniles have been found to migrate down shore in the autumn of their third year (Caron et al. 1993) and compete for burrows with mature, established adults. These interactions can be highly aggressive and often end in mortality or the expulsion of the intruder (Miron et al. 1992a). Newly settled juveniles are known to occur in high densities in the upper intertidal zone (Miron \& Desrosiers 1990), so intra-specific competition for space and food must also exist at this stage. The times during the life-history of $N$. virens when intra-specific competition generally occurs are when interacting with conspecifics outside of the burrow, i.e. when migrating lower down the shore where older animals are already established (Miron 1988, Miron \& Desrosiers 1990). It seems reasonable, therefore, that competition is also likely to occur when post-larval $N$. virens are settling in high densities on the higher levels of the shore and becoming established in the first few centimetres of sediment.

Nereis virens exhibits highly synchronized breeding in which individuals have been observed to spawn at the times of high tide at night associated with spring tides during the early spring (Bass \& Brafield 1972). Observations of natural spawning events, however, often reveal that some individuals may spawn in consecutive spring tide periods (G. J. Watson pers. comm.). There is therefore some variation in the responses of individual worms to a common set of environmental inputs, and such variation may have a heritable component. Such variation would deliver batches of larvae to the post-settlement environment at semi-lunar intervals as observed by Desrosiers et al. (1991). This is reminiscent of the situation observed in perhaps the most famous example of synchronized spawning among polychaetes, the Pacific palolo worm Palola viridis, in which the bulk of the population spawn during a single lunar phase, but some individuals may be observed to have spawned during the 'wrong' tidal cycle 30 d earlier or later (Caspers 1984, discussion in Bentley et al. 2001).

If competition for space and food is present throughout the life-history of Nereis virens, could it produce a selective pressure to be the first post-larvae to settle and become established in the soft-sediment habitat? $N$. virens has been shown to breed earlier in the year than the time of optimum seawater temperature for fertilization and early development (Lewis 2002, Lewis et al. 2002). If strong intra-specific competition exists between post-larvae during and just after settlement, this might produce a selective pressure to breed earlier than the optimum time for fertilization, in order to become established and prevent being out-competed by other post-larvae. Such a selective pressure would bring the breeding time forward until some other factor, for example a factor influencing adult reproductive value, comes into effect.

Here we report on a series of laboratory experiments conducted to test the hypothesis that pre-emptive competition between 2 cohorts of Nereis virens post-larvae, arriving to a patch of sediment early and late, confers a fitness advantage to the first arrivals and hence forms a selective pressure that maintains early reproduction. We examine whether survival and/or growth of $N$. virens post-larvae is enhanced or diminished according to the prior presence or subsequent arrival of other conspecific post-larvae in a patch of sediment. 


\section{MATERIALS AND METHODS}

Larval rearing technique. Mature cultured Nereis virens were obtained from Seabait, Lynemouth, UK. Gametes were collected from the coelomic cavity using a $1 \mathrm{ml}$ syringe with a $21 \mathrm{~g}$ hypodermic needle inserted between 2 segments in the posterior of the worm. Sperm samples were assessed for maturity by diluting a small amount with seawater and checking for active sperm using a light microscope. A fertilization test was conducted to assess the fertilizability of the oocytes. If a jelly coat was observed to form after the addition of sperm, the gametes were assumed to be suitable for use in these experiments. Fertilizations were conducted by adding the collected oocytes and $1 \mathrm{ml}$ of 'dry' sperm to a large glass crystallizing dish containing $200 \mathrm{ml}$ twice filtered seawater (TFSW) at $10^{\circ} \mathrm{C}$. The dish was agitated occasionally for a period of 10 min to prevent the sperm becoming pooled on the bottom of the dish. The embryos and resulting larvae were reared at $12^{\circ} \mathrm{C}$ and under continuous illumination, to the 3 -setiger post-larval stage prior to use in these experiments.

Experimental set-up. To simulate a patch of sediment that can be saturated by settling post-larvae, small glass crystallizing dishes (measuring $7 \times 7 \times 4 \mathrm{~cm}$ ) were used, containing a thin layer of sand (previously autoclaved) approximately 1 to $2 \mathrm{~cm}$ in depth, and $200 \mathrm{ml}$ of TFSW. Two batches of Nereis virens with separate fertilization dates were used to simulate postlarvae arriving early and late to a patch of sediment. The post-larvae were added to the crystallizing dishes and placed into the experimental conditions at the 3 -setiger stage, which is the point at which they begin to settle on the sediment surface (Bass \& Brafield 1972). Early post-larvae were added at the beginning of the experiment and late post-larvae were added after $4 \mathrm{wk}$ (except in the experiment on the effect of age difference). In all experiments the time interval was the same as the time difference between the fertilization dates for the 2 batches of $N$. virens, so that the postlarvae entered the sediment at the same developmental stage.

The crystallizing dishes were kept in environmental cabinets with controlled temperature $\left(5,10\right.$ or $\left.15^{\circ} \mathrm{C}\right)$ and photoperiod (either $16 \mathrm{~h}$ light: $8 \mathrm{~h}$ dark or $8 \mathrm{~h}$ light: $16 \mathrm{~h}$ dark) regimes, depending on the experimental treatment. The seawater in the dishes was replaced each week with fresh TFSW. In order to retain the post-larvae, $3 / 4$ of the original water was gently poured over a $150 \mu \mathrm{m}$ mesh, being careful not to disturb the

\footnotetext{
${ }^{1}$ Marine Microalgae Concentrate, produced by Reed Mariculture. Sachets kept frozen at $-20^{\circ} \mathrm{C}$ until required. Diluted with TFSW to $10^{6}$ cells $\mathrm{ml}^{-1}$ immediately prior to use
}

sediment at the bottom of the dish. Fresh TFSW was poured over the upturned mesh into the dishes to backwash any escaped post-larvae back into the dish. The post-larvae were fed a constant amount of an algal ${ }^{1}$ solution once a week.

The initial early post-larvae were added to the crystallizing dishes at a density of $30 \mathrm{ind}$. dish ${ }^{-1}$, equivalent to 2000 ind. $\mathrm{m}^{-2}$. This figure closely approximates to the lower end of the density range for settling larvae determined by Desrosiers et al. (1991) for the population at the St. Lawrence Estuary (2421 to 4073 ind. $\mathrm{m}^{-2}$ ), yet is not so high as to cause the population to 'crash' in the experimental conditions. Nereis virens were added at the 3 -setiger post-larval stage having just been fed for the first time. Second batches of 3-setiger post-larvae (late post-larvae) were added 4 wk later (except in Expt 3) at the same density of 2000 ind. $\mathrm{m}^{-2}$. Three replicate dishes for each treatment were set up, and $4 \mathrm{wk}$ after the addition of the late post-larvae the experiment was terminated and each dish sampled.

Controls. For each environmental condition 3 replicate control dishes were set up containing 30 Nereis virens post-larvae, for both the early and late batches, to which no extra animals were added. Percentage survival and size were measured at the end of each experiment for each batch of $N$. virens used, to enable generalized survival and growth characteristics to be determined for each of the conditions used. (These set-ups are in accordance with the 'simplest competition experiment' design suggested by Underwood 2000.)

Sampling. At the end of the experimental period the post-larval Nereis virens were removed from the sediment by washing them out onto a $150 \mu \mathrm{m}$ mesh using TFSW, then back-washing any retained post-larvae into a glass crystallizing dish. The recovered postlarvae were fixed in $4 \%$ formaldehyde and examined under a light microscope. The surviving early and late post-larvae were counted, measured and the number of segments recorded.

Post-larval staining technique. To distinguish between the early and late post-larvae when sampling at the end of the experimental period, the vital dye Neutral red was used to stain the late post-larvae. Neutral red (3-Amino-7-dimethylamino-2-methylphenazine hydrochloride) is a conspicuous vital dye often used as an immersion stain for various invertebrate species (e.g. Smith \& Present 1983, Howard 1985, Kelly et al. 1998). A series of toxicity tests revealed a concentration of $0.01 \%$. Neutral red had no effect on survival compared with an unstained control and resulted in a conspicuous red staining of the postlarvae that was still visible 1 mo after staining. A concentration of $0.01 \%$ was therefore used to stain the Nereis virens post-larvae in the competition experi- 
ments. Fresh Neutral red solution at $0.01 \%$ was prepared for each staining procedure from a $1 \%$ stock solution prepared in TFSW. The solution was placed on a magnetic stirrer for $10 \mathrm{~min}$ prior to use. $N$. virens post-larvae at the 3 -setiger stage were concentrated onto a $150 \mu \mathrm{m}$ mesh, which was then placed into the Neutral red solution. After $1 \mathrm{~h}$ the mesh was removed from the solution and the post-larvae washed with clean TFSW. The post-larvae were back-washed off the mesh with TFSW into a large crystallizing dish. After $10 \mathrm{~min}$ the post-larvae were examined to check that they were alive and active.

A reverse staining experiment was also conducted to reveal any effects of staining on post-larval behaviour that may have affected the outcome of these competition experiments. Analysis of the results using a 2-way ANOVA revealed no significant differences between the outcome of experiments in which the late postlarvae were stained when compared to experiments in which the early post-larvae were stained (the same batches of larvae were used in both experiments). No significant effect of the stain on late post-larval survival ( $p=0.895$ ) or early post-larval survival $(p=0.319)$ was observed.

Experimental design. Expt 1-temperature: Experiments were conducted to test the hypothesis that intraspecific competition between Nereis virens post-larvae inhabiting a patch of sediment will be more pronounced at higher temperatures. Two separate competition experiments were set up, using the method described above, using environmental cabinets set at different temperatures. The first experiment used $N$. virens from fertilizations in November and December 2000 and was run at 10 and $15^{\circ} \mathrm{C}$. This experiment was then repeated using larvae from fertilizations at the beginning and end of May 2001 and a $5^{\circ} \mathrm{C}$ treatment was included. A photoperiod regime of $18 \mathrm{~h}$ light:6 h dark (long days) was used for both experiments. Stained late post-larvae were added $4 \mathrm{wk}$ after the unstained early post-larvae and food was constant at $1 \mathrm{ml}$ of algal solution $\mathrm{wk}^{-1} \mathrm{dish}^{-1}$.

Expt 2-photoperiod: Last (2000) has demonstrated that growth rates of juvenile Nereis virens are influenced by photoperiod. Consequently it was of interest to know whether the strength of intra-specific competition between post-larvae was also influenced by photoperiod. Since the time of breeding for $N$. virens is in early spring, the photoperiod experienced by latearriving post-larvae will be greater than experienced by early-arriving post-larvae.

Experiments were conducted to test the hypothesis that intra-specific competition between Nereis virens post-larvae inhabiting a patch of sediment will be more pronounced under conditions of longer photoperiod. Competition experiments were set up as de- scribed above using environmental cabinets at $10^{\circ} \mathrm{C}$ set at long-day photoperiod (16 h light:8 h dark) and short-day photoperiod ( $8 \mathrm{~h}$ light:16 h dark). $N$. virens from fertilizations in December and January 2000-2001 were used. Stained late post-larvae were added 4 wk after the unstained early post-larvae and food was constant at $1 \mathrm{ml}$ of algal solution $\mathrm{wk}^{-1} \mathrm{dish}^{-1}$. This experiment was later repeated at $15^{\circ} \mathrm{C}$ using different batches of $N$. virens from fertilizations at the beginning and end of May 2001.

Expt 3-effect of age difference between early and late arrivals: Experiments were conducted to test the hypothesis that intra-specific competition between Nereis virens post-larvae inhabiting a patch of sediment becomes more pronounced with increasing age difference between batches. Competition experiments were set up using the method described above in environmental cabinets set at $10^{\circ} \mathrm{C}$, with long-day photoperiod (18 h light:6 h dark). Stained late post-larvae were added 2, 4 and $6 \mathrm{wk}$ after the unstained early postlarvae at a density of $2000 \mathrm{~m}^{-2}$. Food was constant at $1 \mathrm{ml}$ of algal solution $\mathrm{wk}^{-1} \mathrm{dish}^{-1}$. These experiments were conducted using $N$. virens from fertilizations in May and June 2001.

Expt 4-food availability: A series of experiments were conducted to test the hypothesis that intraspecific competition between Nereis virens post-larvae inhabiting a patch of sediment becomes more pronounced with decreasing food availability. Competition
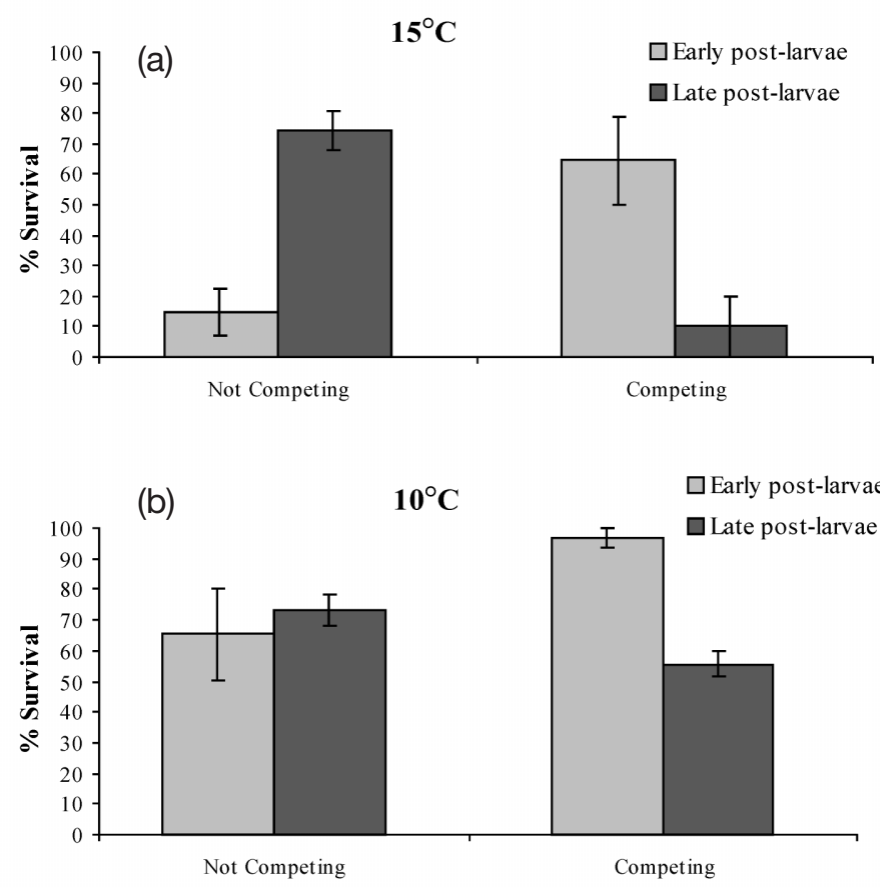

Fig. 1. Nereis virens. Effect of temperature on pre-emptive competition in post-larvae reared at (a) $15^{\circ} \mathrm{C}$ and (b) $10^{\circ} \mathrm{C}$ (data as mean $\pm \mathrm{SE}$ ) 
experiments were set up using the method described above in environmental cabinets set at $10^{\circ} \mathrm{C}$, with longday photoperiod (18 h light:6 h dark). Stained late postlarvae were added $4 \mathrm{wk}$ after the unstained early postlarvae. Three different food treatments were used. One treatment received a constant $1 \mathrm{ml}$ of algal solution $\mathrm{wk}^{-1} \mathrm{dish}^{-1}$. A double food treatment of $2 \mathrm{ml}$ per algal solution was used. In the third treatment the amount of food was increased from $1 \mathrm{ml}$ to $2 \mathrm{ml}$ as the late postlarvae were added to give a constant food:individual ratio throughout the experiment. This experiment was conducted using $N$. virens from fertilizations at the beginning and end of May 2001.

Statistical analysis. The arcsine transformation was used to normalize the observed survivorship initially expressed as percentage survival. This process made the use of parametric statistics to compare treatments valid. Bartlett's and Levene's tests were used to check for homogeneity of variance between treatments for each experiment. ANOVA was used to compare treatments, following the procedures available in the statistical package Minitab.

\section{RESULTS}

\section{Expt 1 -effect of temperature on competition}

The effects of temperature on the strength of competition between early and late Nereis virens post-larvae are shown in Figs. $1 \& 2$. In the first temperature experiment conducted at 10 and $15^{\circ} \mathrm{C}$ (Fig. 1) survival of late post-larvae was reduced when competing with early post-larvae at both temperatures. This decrease in survival was greater at $15^{\circ} \mathrm{C}$ (from $74.4 \%$ with no early post-larvae present, to $10 \%$ with early post-larvae present) than at $10^{\circ} \mathrm{C}$ (from $73.3 \%$ with no early postlarvae present, to $55.6 \%$ with early post-larvae present). The survival of early post-larvae was increased when competing with late post-larvae at both temperatures. This increase in early post-larval survival was greater at $15^{\circ} \mathrm{C}$ (from $15 \%$ with no late post-larvae present, to $64.4 \%$ with late post-larvae present) than that at $10^{\circ} \mathrm{C}$ (from $65.5 \%$ with no late post-larvae present, to $96.7 \%$ with late post-larvae present). Statistical analysis using a 2-way ANOVA revealed a significant effect of competition on the survival of late post-larvae $(\mathrm{p}=0.001)$. A significant effect of temperature $(\mathrm{p}=$ 0.018 ) and an interaction of temperature and competition $(p=0.015)$ on late post-larval survival were also present.

A second temperature experiment was conducted in which a $5^{\circ} \mathrm{C}$ treatment was included in addition to the 10 and $15^{\circ} \mathrm{C}$ treatments (Fig. 2). At this $5^{\circ} \mathrm{C}$ treatment the results observed were somewhat different to those
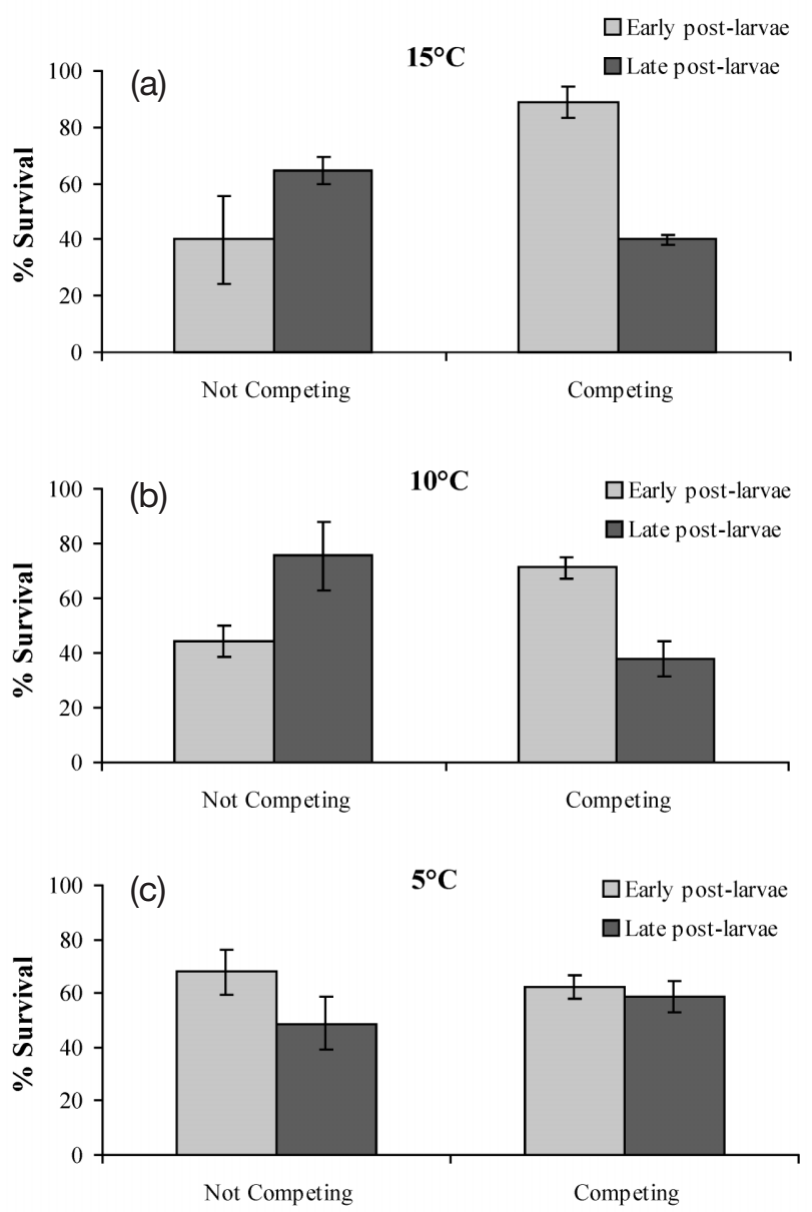

Fig. 2. Nereis virens. Effect of temperature on pre-emptive competition in post-larvae reared at (a) $15^{\circ} \mathrm{C}$ (b) $10^{\circ} \mathrm{C}$ and (c) $5^{\circ} \mathrm{C}$ (data as mean $\pm \mathrm{SE}$ )

observed at the higher temperatures. No significant reduction in late post-larval survival was observed at $5^{\circ} \mathrm{C}$ (1-way ANOVA, $\mathrm{p}=0.416$, Fig. 2), nor was any significant positive effect of late post-larvae on survival of the early cohort. In this experiment the observed reduction in late larval survival in the presence of early post-larvae when reared at $10^{\circ} \mathrm{C}$ was not statistically significant (1-way ANOVA, p = 0.103). The results observed at $15^{\circ} \mathrm{C}$ were substantially as before, as intraspecific competition between the 2 age classes produced a highly significant reduction in the survival of late-arriving post-larvae ( $\mathrm{p}=0.011)$.

These results suggest that there is an effect of temperature on intra-specific post-larval competition in Nereis virens. There was no competitive effect on survival detected at $5^{\circ} \mathrm{C}$, but a highly significant effect of competition on late post-larval survival was evident at $15^{\circ} \mathrm{C}$. The competitive effect observed at $10^{\circ} \mathrm{C}$ varied between the 2 experiments. The strength of this temperature effect appears to depend on the batch of post-larvae involved. This is not surprising since post-larval quality 
Table 1. Nereis virens. Mean size of 'early' post-larvae, with no 'late' post-larvae present, at the end of the 2 month experimental period in the different temperature treatments

\begin{tabular}{|lcr|}
\hline Temp. $\left({ }^{\circ} \mathrm{C}\right)$ & Mean size $(\mu \mathrm{m})$ & \multicolumn{1}{c|}{ SE } \\
\hline 5 & 444.7 & 11.9 \\
10 & 589.7 & 52.9 \\
15 & 1150.9 & 232.0 \\
\hline
\end{tabular}

is likely to affect both competitive ability and growth rate. A significant effect of temperature on the growth rates of the post-larvae was also observed (Table 1). Analysing pooled data from the 2 temperature experiments, using a 1-way ANOVA, revealed a significant difference in mean size for the late post-larvae reared at the 3 temperature treatments $(p=0.019)$. The greater growth rates observed at higher temperature result in a greater disparity in size between the 2 batches of $N$. virens at the time of late post-larval arrival. Foraging activity of the post-larvae may also be greater at higher temperatures, leading to a greater frequency of intraspecific post-larval encounters.

Red staining around the gut area of the recovered early post-larvae was frequently observed for both temperature experiments, suggesting that these post-larvae had been feeding on the smaller stained late post-larvae.

\section{Expt 2-effect of photoperiod on competition}

The effects of photoperiod on intra-specific postlarval competition in Nereis virens are shown in Figs. 3 $\& 4$. The first photoperiod experiment was conducted from December 2000 to January 2001 at $10^{\circ} \mathrm{C}$ (Fig. 3). A similar competition effect, i.e. a decrease in survival of late post-larvae when in the presence of early postlarvae, was observed under both long- and short-day treatments of photoperiod. Statistical analysis of the data using a 2-way ANOVA revealed a significant effect of competition on survival of late larvae ( $\mathrm{p}=$ 0.011). A significant effect of photoperiod was also present $(p=0.035)$ but there was no significant interaction term $(\mathrm{p}=0.349)$. At long day photoperiod (16 h light: $8 \mathrm{~h}$ dark) a small increase was observed in mean survival of early larvae when late post-larvae were added. In the short-day photoperiod treatment ( $8 \mathrm{~h}$ light:16 h dark), however, reduced survival of both early and late post-larvae was observed when present together.

The second photoperiod experiment was conducted from May to June 2001 at $15^{\circ} \mathrm{C}$ (Fig. 4). The competition effect, as previously described, was greater at this higher temperature. The survival of late post-larvae was lower when reared in the presence of early postlarvae for both photoperiodic treatments. The survival of early post-larvae was higher when late post-larvae were added compared to survival rates observed when no late post-larvae were present. A 2-way ANOVA was used to determine if there was an additional effect of photoperiod on intra-specific competition. This revealed a significant effect of competition on late post-larval survival ( $p=0.001$ ) as in the previous experiments. A small but significant effect of photoperiod on post-larval survival was also present $(p=0.036)$ but no significant interaction term $(\mathrm{p}=0.778)$.

Comparing the mean size of early non-competing larvae from the 2 photoperiod treatments (Table 2), using a 2 sample $t$-test, reveals that there is no significant effect of photoperiod on growth rate of the postlarvae at $10^{\circ} \mathrm{C}(\mathrm{p}=0.72)$ or at $15^{\circ} \mathrm{C}(\mathrm{p}=0.96)$.

Table 2. Nereis virens. Mean size of 'early' non-competing post-larvae from the 2 treatments of photoperiod at the end of the experimental period

\begin{tabular}{|lccr|}
\hline Temp. $\left({ }^{\circ} \mathrm{C}\right)$ & Photoperiod & Mean size $(\mu \mathrm{m})$ & \multicolumn{1}{c|}{ SE } \\
\hline 10 & Long day & 727.4 & 27.9 \\
& Short day & 694.1 & 65.8 \\
15 & Long day & 919.6 & 100.0 \\
& Short day & 925.5 & 32.1 \\
\hline
\end{tabular}
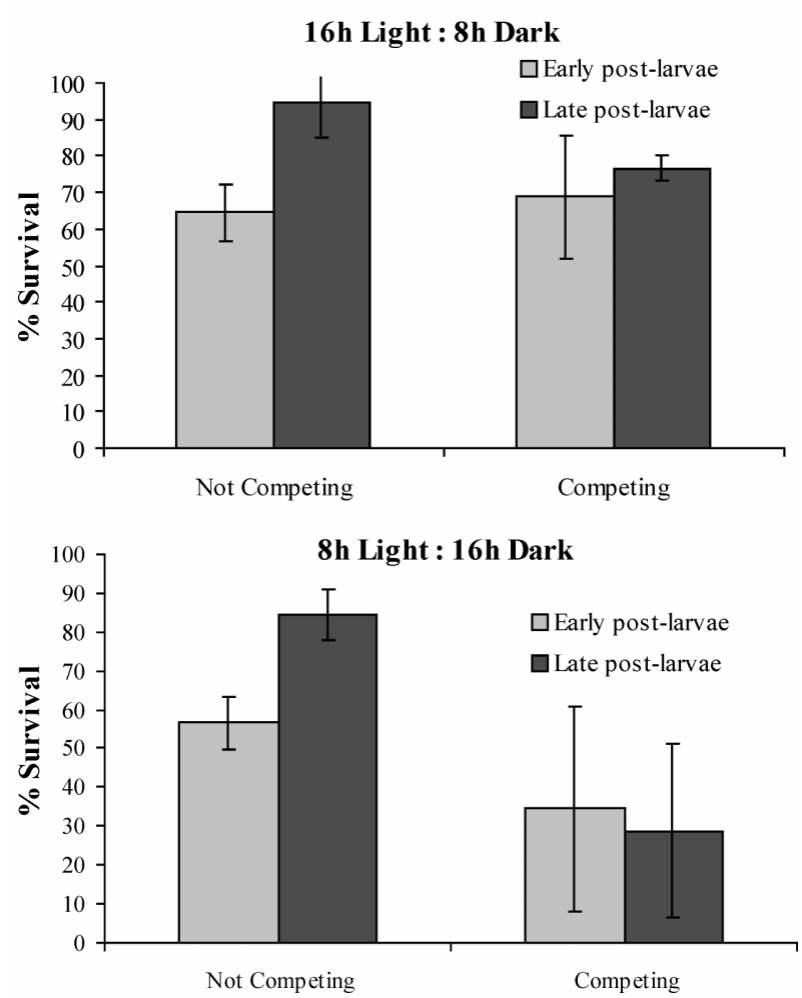

Fig. 3. Nereis virens. Effect of photoperiod on intra-specific competition in post-larvae reared at $10^{\circ} \mathrm{C}$ (data as mean $\pm \mathrm{SE}$ ) 

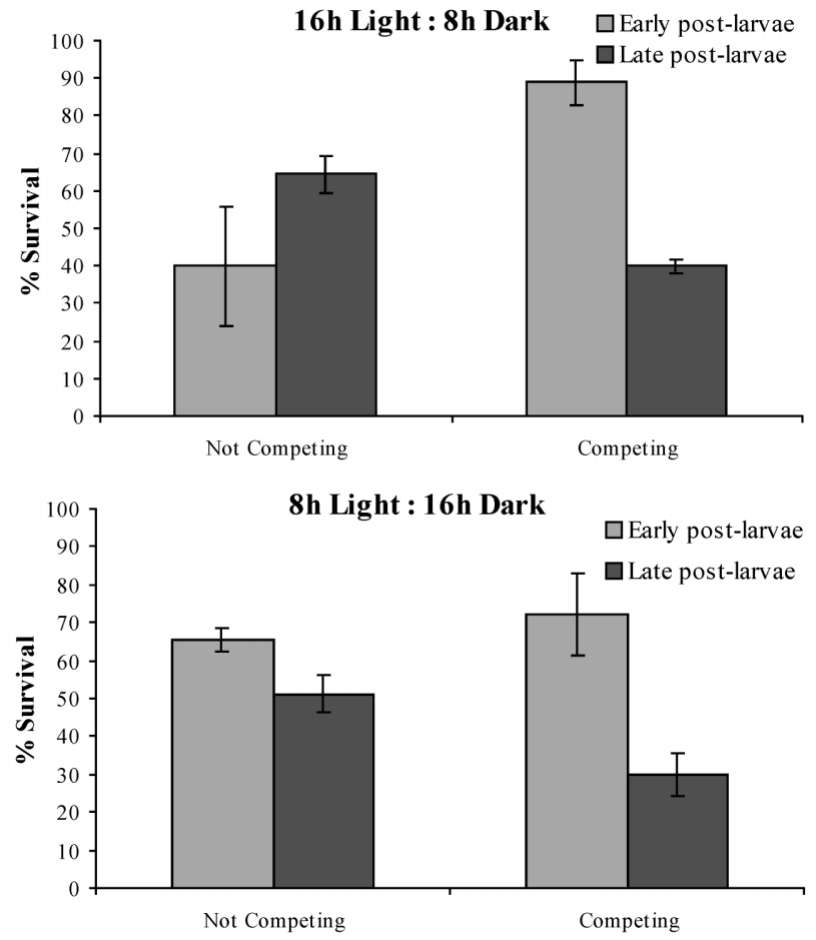

Fig. 4. Nereis virens. Effect of photoperiod on intra-specific competition in post-larvae reared at $15^{\circ} \mathrm{C}$ (data as mean $\pm \mathrm{SE}$ )

The photoperiod experienced by Nereis virens postlarvae therefore appears to have had an impact on their survival, but no influence on growth rate. The lack of significant interaction term suggests that photoperiod had a relatively minor effect on the strength of intra-specific competition. According to Last \& Olive (1999) lower foraging activity and hence low growth rates would be expected in adult $N$. virens reared under a light:dark cycle of $8: 16 \mathrm{~h}$. The fact that a short photoperiod regime ( $8 \mathrm{~h}$ light: $16 \mathrm{~h}$ dark) did not reduce the competitive response in these experiments suggests that post-larvae do not show the same behavioural response to photoperiod as adult $N$. virens. It is possible that the response of $N$. virens to photoperiodic changes is affected by their previous photoperiodic history, and that in order to exhibit reduced foraging behaviour under short-day conditions, individuals must first experience long-day conditions.

\section{Expt 3-effect of age difference between cohorts on competition}

The effect of the time difference between the arrival of the early and late Nereis virens post-larvae to a patch of sediment was investigated and the results are shown in Fig. 5. An age difference of just $2 \mathrm{wk}$ between the early and late post-larvae produced no significant competition effect. No reduction in the survival of late post-larvae when reared in the presence of early larvae was observed (1-way ANOVA, $p=0.99$, mean survival of late post-larvae was $70 \%$ for both treatments).

A reduction of late post-larval survival when reared in the presence of early post-larvae was observed when the age difference between the 2 batches was 4 and $6 \mathrm{wk}$. This reduction in late postlarval survival (from $75.6 \%$ in the absence of early post-larvae to $37.8 \%$ in the presence of early postlarvae) was not significant with an age difference between batches of 4 wk (1-way ANOVA, $\mathrm{p}=0.103$ ). However an age difference of 6 wk produced a significant reduction in late post-larval survival, from $65.6 \%$ in the absence of early post-larvae to $43.3 \%$ in the presence of early post-larvae (1-way ANOVA, $p=0.043)$. This leads to the conclusion that there was a significant effect of the time interval between early and late post-larval settlement on the strength of the intra-specific effect, whereby competition is increased with a greater age difference between post-larvae.
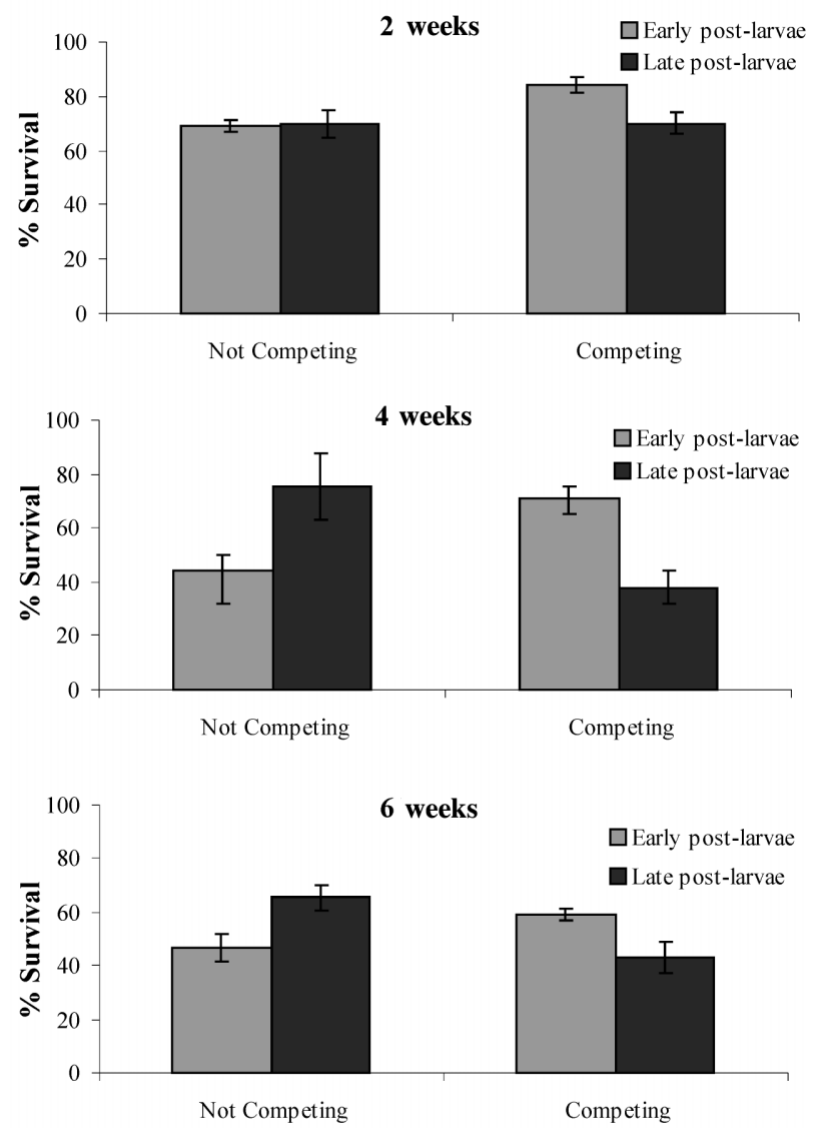

Fig. 5. Nereis virens. Effect of age difference between cohorts on intra-specific competition in post-larvae reared at $10^{\circ} \mathrm{C}$ (data as mean $\pm \mathrm{SE}$ ) 
Table 3. Nereis virens. Mean sizes of 'early' non-competing post-larvae at end of the experimental period for the 3 time intervals at which 'late' post-larvae were added. Dishes were sampled $4 \mathrm{wk}$ after the addition of the 'late' post-larvae (i.e. at 6,8 and $10 \mathrm{wk}$ after the start of the experiment)

\begin{tabular}{|lcr|}
\hline Time interval $(w k)$ & Mean size $(\mu \mathrm{m})$ & SE \\
\hline 2 & 483.8 & 2.2 \\
4 & 591.6 & 104.0 \\
6 & 599.4 & 83.2 \\
\hline
\end{tabular}

An increase in the survival of early post-larvae was observed when late post-larvae were added 4 or $6 \mathrm{wk}$ later. This suggests that the first post-larvae to settle gained some benefit from later arrivals. A 2-way ANOVA using the early post-larvae survival data revealed both competition and time of late post-larval arrival have a significant effect on survival $(p<0.001$ for both) though there is no significant interaction term $(p=0.242)$. This result is likely to be due to competition within the early larvae. The effect of the addition of late post-larvae on early post-larval survival was greater when the late post-larvae were added after $4 \mathrm{wk}$. If the late post-larvae do indeed act as an additional food source to the older and larger early Nereis virens post-larvae, then the greater period of time without this additional food might result in greater competition within the early post-larvae population, resulting in greater mortality.

Table 3 shows the mean sizes for the early larvae at the times of addition of late larvae. Whilst the early post-larvae had grown in the time intervals used, this increase in growth was not significant (1-way ANOVA, $p=0.531$ ). At 2 wk the difference in size was not significant, but was enough to reduce the presence of the competitive effect.

\section{Expt 4-effect of food availability on competition}

The effect of food availability on competition between early and late Nereis virens post-larvae was investigated and the findings are summarized in Fig. 6. In all 3 treatments where additional food was provided, the competitive effect was still observed, i.e. a reduction in survival of the late post-larvae was observed in the presence of early post-larvae. The provision of additional food did not appear to suppress this competitive effect. This is confirmed by a 2 -way ANOVA on arcsine-transformed survival percentages for the late post-larvae. This revealed a significant competition effect $(p=0.001)$ but no significant effect of the food treatment $(p=0.729)$ or any interaction term $(p=0.267)$.
The percentage survival measured for the early postlarvae was greater when late post-larvae were added than when no late post-larvae were present, in all $3 \mathrm{food}$ treatments. Analysis of the early post-larvae data using a 2-way ANOVA again revealed a significant competition effect $(p=0.003)$ but there was no significant effect of food treatment on early post-larval survival $(p=0.101)$ and there was no interaction term ( $\mathrm{p}=0.092)$.

Analysing the mean size of early non-competing post-larvae from the normal and double food treatments (Table 4) using a 2-sample $t$-test revealed that

Table 4. Nereis virens. Effect of food availability on size of 'early' non-competing post-larvae at the end of the experimental period ('normal' $=1 \mathrm{ml}$ algal solution $\mathrm{wk}^{-1} \mathrm{dish}^{-1}$, 'double' $=2 \mathrm{ml}$ algal solution $\mathrm{wk}^{-1} \mathrm{dish}^{-1}$ )

\begin{tabular}{|lcr|}
\hline Food availability & Mean size $(\mu \mathrm{m})$ & SE \\
\hline 'Normal' & 591.6 & 104.0 \\
'Double' & 657.3 & 45.4 \\
\hline
\end{tabular}
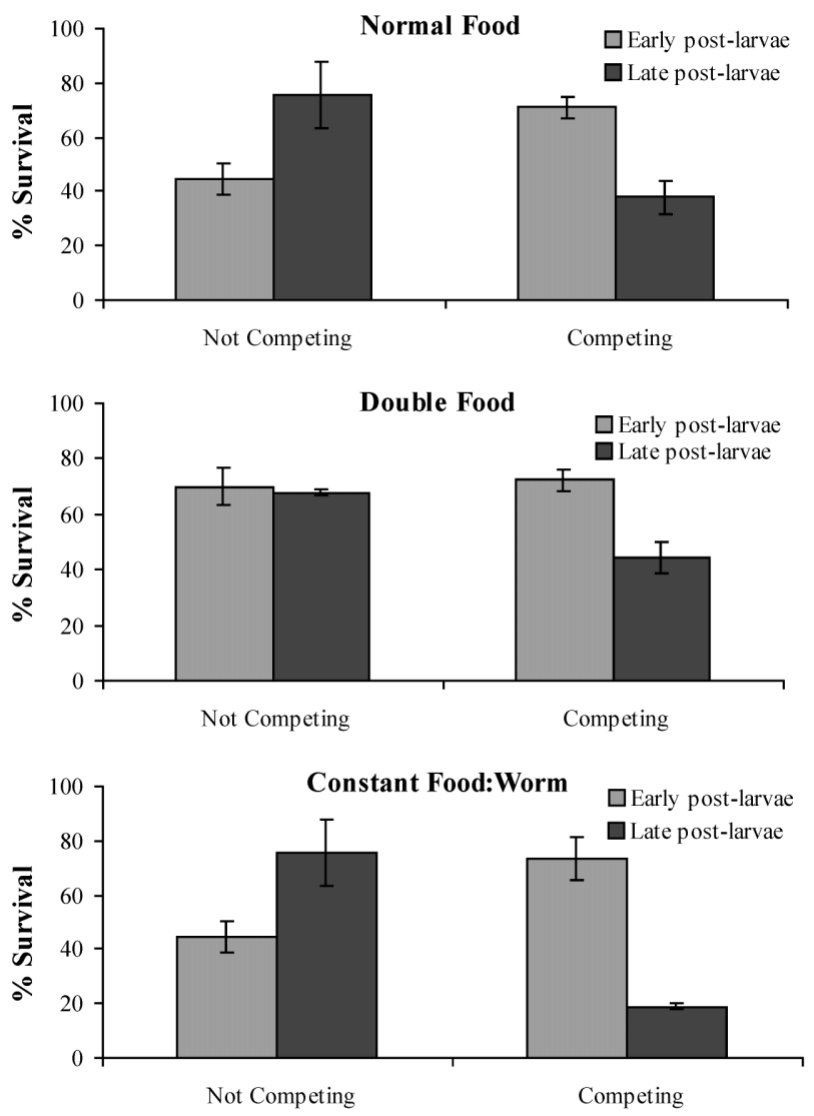

Fig. 6. Nereis virens. Effect of food abundance on intraspecific competition in post-larvae reared at $10^{\circ} \mathrm{C}$ (data as mean $\pm \mathrm{SE}$ ) 
there was no significant effect of food availability ( $\mathrm{p}=$ 0.62 ) on size and hence growth during the experimental period. Since an increase in food availability had no measurable effect on post-larval growth, it can be concluded that Nereis virens post-larvae were not foodlimited at the 'normal' concentration of food used in Expts 1 to 3 . These results also suggest that the reduced survival of the late competing post-larvae was not due to decreased food availability but was a result of a direct interaction with post-larvae that occupied the sediment patch earlier. Red staining of the guts of early competing post-larvae was frequently observed in many of the experimental treatments, suggesting that the early post-larvae were using the smaller late post-larvae as an additional food source in preference to the food provided. On a number of occasions large (unstained) early post-larvae were observed eating smaller (stained) late post-larvae (although photographic evidence was not possible). The smaller postlarvae were consumed 'tail first' in each case. This would explain the increased survival of early postlarvae when late post-larvae were added, that was observed in many of the experimental treatments.

\section{DISCUSSION}

These experiments have demonstrated the operation of what may be termed pre-emptive intra-specific competition between settling Nereis virens post-larvae arising from differing fertilization dates. Whilst $N$. virens exhibits highly synchronized breeding, observations of spawning events have revealed that some individuals may spawn during consecutive spring tide periods (G. J. Watson pers. comm.). This slight variation in the responses of individual worms would deliver batches of larvae to the post-settlement environment at semi-lunar intervals (as observed by Desrosiers et al. 1991) and produce more than 1 cohort of larvae, as replicated by these experiments.

In laboratory simulations post-larvae arriving late to a patch of sediment were observed to have reduced survival due to competitive interactions with previously established early post-larvae. These competitive interactions appear to become greater with increased size difference between the 2 cohorts of Nereis virens post-larvae. Factors affecting this size difference include the time interval between settlement of the 2 batches and the growth rate of the post-larvae, which in turn is affected by temperature. Photoperiod is known to affect growth rates in N. virens (Last 2000) but was found to have no effect on the outcome of these competition experiments.

The decreased survival of late post-larvae in the presence of previously established post-larvae may be construed as a result of density-dependent processes, since the total number of animals in the experimental dishes were twice that of the control dishes. If this were the case then a reduction in early post-larval survival would also be expected in the experimental dishes. However, survivorship of early post-larvae was increased by the addition of late post-larvae in the majority of the experiments conducted. This suggests that it is in fact a competitive interaction whereby the early cohort out-competes the late cohort and gains an advantage from the presence of the additional postlarvae.

Many of the competing early larvae were observed to have red staining around the gut area, suggesting that the late post-larvae were acting as an additional food source to them. Early post-larvae were actually observed eating smaller late individuals on a few occasions. No effect of food availability on the intra-specific competitive effect was observed. This further suggests that the lower survival rate of the late competing postlarvae was due to intra-specific interactions and that it was not simply a result of a decrease in the food available ind.$^{-1}$ due to the increase in the number of individuals present. Cannibalism has been observed in adult Nereis virens (Kristensen 1984, Miron et al. 1992b, K. S. Last pers. comm.) so it is not surprising to also find it present in the post-larval form (newly settled but metamorphosed). Increasing the food concentration did not reduce this effect, and so it could be concluded that $N$. virens prefers eating conspecifics to the algae provided as food in these experiments. In the natural environment the food sources available to settling $N$. virens larvae would be more varied, and so this effect may be reduced. Most reports on the feeding habits of young $N$. virens, however, suggest algae and detritus as the main food sources (Fauchauld \& Jumars 1979).

In the population of Nereis virens in the St. Lawrence Estuary studied by Desrosiers et al. (1991), initial settling densities were measured and found to be high (2421 to 4073 ind. $\mathrm{m}^{-2}$ ). These densities correspond well with the range used in these experiments. These experiments can therefore be considered a fair representation of what might occur to late-arriving postlarval $N$. virens under natural conditions. In the study by Desrosiers et al. (1991) 2 peaks of 3-setiger postlarvae were recorded 2 wk apart. This 'double' peak was not recorded at any later developmental stage. This could be due to the 2 peaks merging, or could be due to the second cohort of post-larvae being outcompeted by the slightly older post-larvae, as suggested by the observations here.

Pre-emptive competition is considered to be the most common form of inter-specific competition among marine organisms (Schoener 1983). In his review of the mechanisms of competition Schoener (1983) defined 
pre-emptive competition as 'competition that occurs when a unit of space is passively occupied by an individual, thereby causing other individuals not to occupy that space before the occupant disappears'. Other definitions of pre-emptive competition include competition for limiting resources other than space, that are available immediately upon becoming unoccupied, e.g. the use of insect hosts by parasitoid wasps (Albrectsen \& Nachman 2001). This type of competition occurs primarily in sessile organisms, such as encrusting algae and sessile marine invertebrates, and is frequently observed in organisms competing for settlement space in the intertidal zone. Descriptions of pre-emptive competition in intra-specific interactions also exist, though these are not as common. Whilst the term pre-emptive competition is normally used to describe exploitative competition (organisms competing for a limiting resource), the use of the term here is valid since an advantage is gained through prior residence.

A selective pressure via inter-specific competition between the post-settlement stages of Nereis virens and other species present in the substrate is also possible though not investigated here. Caron et al. (1996) investigated competitive interactions between adult $N$. virens and Nephtys caeca and showed that the result of the competitive interaction was determined at least in part by the order in which individual worms entered the substrate. In northeast England the postsettlement larvae of $N$. virens are unlikely to compete directly for habitat patches with the larvae of $N$. caeca or Nephtys hombergi due to differences in the timing of recruitment. The larvae of the Nephtys sp. are recruited in June to July following spawning in May and a lengthy pelagic developmental phase (Olive 1977, Olive \& Morgan 1983). There is also spatial separation between species as $N$. virens larvae settle mainly at high and intermediate levels of the intertidal zone (Miron \& Desrosiers 1990) whilst N. caeca settle sub-tidally (Caron et al. 1996). An investigation of the more likely inter-specific interaction between post-larvae of $N$. virens and Nereis diversicolor may prove fruitful. Both species are found in estuaries in northeast England but the adults occupy different zones within the same estuary (Kristensen 1984).

The presence of pre-emptive competition between settling Nereis virens larvae and post-larvae, such as demonstrated here, would produce a selective pressure to be the first larvae to settle in a patch of sediment. A fitness benefit would be gained from early reproduction by increasing post-larval survival (a component of $\mathrm{S}[\alpha]$ from Charnov's 1997 fitness equation, see also Olive et al. 2000, 2001). The recent investigations into the seasonal impacts on fertilization and development in $N$. virens (Lewis 2002, Lewis et al.
2002) demonstrated that breeding in $N$. virens occurs prior to the onset of optimum temperature conditions for fertilization and early development. The presence of this strong pre-emptive competition between settling larvae provides a possible explanation for the maintenance of this 'early reproduction' strategy.

The acquisition of a fitness benefit through prior residence has been demonstrated in several studies of salmonid species. Prior residence affects the outcome of intra-specific interactions in the territorial species Salmo salar (Cutts et al. 1999), Oncorhynchus kisutch (Mason \& Chapman 1965) and O. mykiss (Chandler \& Bjornn 1988). In all of these studies a size gap was established and maintained by the prior resident with respect to later emerging fry. It has also been demonstrated that competitive ability of juvenile salmon in the first few post-emergence months influence subsequent life-history strategies through their effect on growth rates (Metcalfe et al. 1989, 1990). These include survival rates and the age at which migration out to sea occurs (Cutts et al. 1999). The influence of this pre-emptive competitive effect on the timing of reproduction in salmonids was not discussed in these studies.

The pre-emptive intra-specific competition discovered here in Nereis virens post-larvae became more significant at higher temperatures but was not measurable at $5^{\circ} \mathrm{C}$. Since maximum fertilization success has been recorded for $N$. virens in the range 15 to $18^{\circ} \mathrm{C}$ (Lewis 2002, Lewis et al. 2002) this means that the closer to the 'optimum' conditions for fertilization that spawning occurs, the greater any competitive effect will be. Thus pre-emptive competition produces a selective pressure for early reproduction since the first individuals to inhabit a patch of previously unoccupied sediment will achieve greater survival and faster growth. There is therefore a strong selective pressure to breed earlier than the time of optimal temperature for fertilization. The earlier reproduction takes place, however, the more unfavourable the temperature becomes for fertilization (Lewis 2002, Lewis et al. 2002) and the less significant the competitive effect would be. At $5^{\circ} \mathrm{C}$ the competitive effect was not measurable, therefore the advantage of being first to become established is removed. Post-larval quality appears to affect the strength of the pre-emptive competitive effect measured by these experiments. It has been demonstrated elsewhere that post-larval quality in $N$. virens is reduced when development occurs at $5^{\circ} \mathrm{C}$ (Lewis 2002). Breeding too early would therefore reduce the quality of the early post-larvae and therefore reduce the fitness benefit associated with being the first to settle.

The release of larvae at times when the water temperature is increasing is thought to reduce the varia- 
tion in the size range of the larvae (Bhaud et al. 1995). This reduction in the juvenile size range has been shown to be advantageous, as it balances the interindividual competition (Cha 1994 cited in Bhaud et al. 1995). Strong intra-specific competition in the juvenile stage has been also been demonstrated in the polychaete Eupolymnia nebulosa (Bhaud et al. 1995). Bhaud et al. (1995) concluded that the juvenile period of $E$. nebulosa was therefore the critical stage in determining the timing of life-cycle events in relation to the annual calendar.

The strong intra-specific competition demonstrated here may be considered to form a selective pressure to maintain synchronized reproduction at a time prior to the onset of optimum conditions for development and at a time when the benefits of prior occupancy are reduced. The optimum time for reproduction in terms of optimizing larval/juvenile survival is likely to be a trade-off between optimal conditions for fertilization and subsequent development, and the pressure to be the first to settle in a patch of sediment. Temperature has opposing influences on these 2 processes, therefore the optimum temperature at which to breed is likely to be somewhere between 5 and $15^{\circ} \mathrm{C}$. Temperatures measured at the time of reproduction for Nereis virens are normally around 8 to $10^{\circ} \mathrm{C}$ (Goerke 1984), which supports this hypothesis. It therefore suggested that the observed timing of reproduction in $N$. virens is a result of balancing selection between these conflicting selective pressures.

The genetic basis for the reaction norms to environmental inputs which maintain the phase relationships between spawning events and the entraining environmental signals are not as yet fully known, although some of the genes involved in the Nereis clock have now been identified and cloned (Kyriakou et al. unpubl. data). It has been demonstrated that a key event is the response to a critical photoperiodic threshold in the autumn (Olive et al. 1998, Rees \& Olive 1999) though the time of breeding may also be modified by the environmental conditions experienced after the time of this key transition (Rees \& Olive 2000).

Indirect evidence suggests that Nereis virens is an invasive species to the North Sea fauna (Reise et al. 1999), having arrived within the last $300 \mathrm{yr}$ from a site of origin in the Eastern Seaboard of the USA or the St. Lawrence Estuary. Populations of $N$. virens in the St. Lawrence Estuary (Desrosiers et al. 1985, 1991, 1994) and in New Brunswick (Snow \& Marsden 1974) are confined in their timing of reproduction by the time of the ice melt, so spawning does not normally occur until May to June. UK populations breed in February and March (Brafield \& Chapman 1967, Bass \& Brafield 1972). Implications are that, freed from the constraint imposed by ice formation in the colder conditions of the Eastern American Seaboard, the breeding season has shifted forwards to a new 'optimum' time. The results of this investigation suggest that 1 component of the natural selection for traits that maintain this pattern of early reproduction is intra-specific competition between post-settlement stages. Establishment of the molecular components of clock function and photoperiodic time-keeping in Nereidae will provide the basis for investigation of genetic loci that may be involved in selection processes maintaining the timing of key lifehistory events and maintaining differences between populations living in different parts of the geographical range.

Acknowledgements. This work was carried out with the support of NERC (grant no. GST/02/2164) as a contribution to the thematic programme DEMA, using facilities made available through grant NERC GR3/JE158. We would like to acknowledge the support given by Seabait through the supply of materials. We would also like to thank A. McLachlan and G. $\mathrm{J}$. Watson for their useful comments on this manuscript.

\section{LITERATURE CITED}

Albrectsen B, Nachman G (2001) Female biased densitydependent dispersal of a tephritid fly in a fragmented habitat and its implications for population regulation. Oikos 94:263-272

Babcock RC (1986) Synchronous spawning of 105 scleractinian coral species on the Great Barrier Reef. Mar Biol 90: 379-394

Babcock RC, Wills BL, Simpson CJ (1994) Mass spawning of corals on a high-latitude coral reef. Coral Reefs 13: 161-169

Bass NR, Brafield AE (1972) The life cycle of the polychaete Nereis virens. J Mar Biol Assoc UK 52:701-726

Bentley MG, Olive PJW, Last KS (2001) Sexual satellites, moonlight and the nuptial dance of worms: the influence of the moon on the reproduction of marine animals. Earth Moon Planets 85-6:67-84

Bhaud M, Cha JH, Duchene JC, Nozias C (1995) Influence of temperature on the marine fauna: what can be expected from a climatic change? J Therm Biol 20:91-104

Brafield AE, Chapman G (1967) Gametogenesis and breeding in a natural population of Nereis virens. J Mar Biol Assoc UK 47:619-627

Bridges TS, Farrar DJ, Gamble EV, Dillon TM (1996) Intraspecific density effects in Nereis (Neanthes) arenaceodentata Moore (Polychaeta: Nereidae). J Exp Mar Biol Ecol 195:221-235

Caron A, Desrosiers G, Retière C, Hudier E (1993) Comparison of demographic parameters relating to natural populations of the polychaete Nereis virens Sars and Nephtys ceaca (Fabricius). Oceanol Acta 16:403-412

Caron A, Desrosiers G, Miron G, Retière C (1996) Comparison of spatial overlap between the polychaetes Nereis virens and Nephtys ceaca in two intertidal estuarine environments. Mar Biol 124:537-550

Caspers H (1984) Spawning periodicity and habitat of the palolo worm Eunice viridis (polychaeta, eunicidae) in the Samoan Islands. Mar Biol 79:229-236

Chandler GL, Bjornn TC (1988) Abundance, growth and 
interactions of juvenile steelhead trout relative to time of emergence. Trans Am Fish Soc 117:432-443

Charnov EL (1997) Trade-off invariant rules for evolutionarily stable life histories. Nature 387:393-394

Clark RB (1959) The tubiculous habit and fighting behaviour of the polychaete Nereis pelagica. Anim Behav 7:85-90

Connell JH (1963) Territorial behaviour and dispersion in some marine invertebrates. Res Popul Ecol 5:87-101

Counihan RT, McNamara DC, Souter DC, Jebreen EJ, Preston NP, Johnson CR, Degnan BM (2001) Pattern, synchrony and predictability of spawning of the tropical abalone Haliotis asinina from Heron Reef, Australia. Mar Ecol Prog Ser 213:193-202

Cram A, Evans M (1980) Stability and lability in the evolution of behaviour in Nereid polychaetes. Anim Behav 28: 483-490

Cutts CJ, Brembs B, Metcalfe NB, Taylor AC (1999) Prior residence, territory quality and life history strategies in juvenile Atlantic salmon (Salmo salar L.). J Fish Biol 55: 784-794

Desrosiers G, Caron A, Olivier M, Miron G (1985) Cycle de development d'une population de Nereis virens (Polychaeta: Nereidae) sur la vive sud de l'estuaire maritime du Saint Laurent. Oceanol Acta 17:178-190

Desrosiers G, Olivier M, Vincent B (1991) Variations de la densité et de la croissance des recrues de l'annelide polychète Nereis virens (Sars) en zone intertidale. Can J Zool 69:560-566

Desrosiers G, Caron A, Olivier M, Miron G (1994) Life history of the polychaete Nereis virens (Sars) in an intertidal flat of the lower St. Lawrence Estuary. Oceanol Acta 17: 683-695

Evans SM (1973) A study of fighting reactions in some Nereid polychaetes. Anim Behav 21:138-146

Fauchald K, Jumars PA (1979) The diet of worms: a study of polychaetes feeding guilds. Oceanogr Mar Biol Annu Rev 17:193-284

Giese AC, Kanatani H (1987) Maturation and spawning. In: Giese AC, Pearse JS (eds) Reproduction in marine invertebrates. Blackwell Scientific Publications, Palo Alto, CA, p 251-329

Goerke H (1984) Temperature dependence of swarming in North Sea Nereidae. Fortschr Zool 29:39-43

Howard RK (1985) Measurements of short-term turnover of epifauna within seagrass beds using an in situ staining method. Mar Ecol Prog Ser 22:163-168

Kelly LS, Snell TW, Lonsdale DJ (1998) Chemical communication during mating of the harpaticoid Tigriopus japonicus. Phil Trans R Soc Lond 353:737-744

Kent AC, Day RW (1983) Population dynamics of an infaunal polychaete: the effect of predators and an adult-recruit interaction. J Exp Mar Biol Ecol 73:185-203

Korringa P (1957) Lunar periodicity. In: Hedgepeth JW (ed) Treatise on marine ecology and paleoecology. Geological Society of America Memoirs \#67, Baltimore, p 917-934

Kristensen E (1984) Life cycle, growth and production in estuarine populations of the polychaetes Nereis virens and Nereis diversicolor. Holarct Ecol 7:249-256

Kubota H (1981) Synchronisation of spawning in the crinoid, Comanthus japonica. In: Clark WH, Adams TS (eds) Advances in invertebrate reproduction (developments in endocrinology). Elsevier, Amsterdam, p 69-74

Last KS (2000) Photoperiodism in the semelparous polychaete Nereis virens (Sars). PhD thesis, University of Newcastleupon-Tyne

Last KS, Olive PJW (1999) Photoperiodic control of growth and segment proliferation by Nereis (Neanthes) virens in relation to state of maturity and season. Mar Biol 134: 191-199

Lewis C (2002) Fitness components of seasonal reproduction in two Polychaeta: Nereis virens (Sars) and Arenicola marina (L.). PhD thesis, University of Newcastle-upon-Tyne

Lewis C, Olive PJW, Bentley MG, Watson G (2002) Does seasonal reproduction occur at the optimal time for fertilization in the polychaetes Arenicola marina L. and Nereis virens Sars? Invertebr Reprod Dev 41:61-71

Mason JC, Chapman DW (1965) Significance of early emergence, environmental rearing capacity and behavioural ecology of juvenile Coho salmon in stream channels. J Fish Res Board Can 22:173-191

Metcalfe NB, Huntingford FA, Graham WD, Thorpe JE (1989) Early social status and the development of life history strategies in Atlantic salmon. Proc R Soc Lond Ser B Sci 236:7-19

Metcalfe NB, Huntingford FA, Thorpe JE, Adams CE (1990) The effects of social status on life history variation in juvenile salmon. Can J Zool 68:2630-2636

Miron G (1988) Distributions et variations intra-population de trois éspeces de Polychaètes de la baie de l'anse á l'orignal, parc national du bic. $\mathrm{PhD}$ thesis, Université du Quebec, Rimouski

Miron G, Desrosiers G (1990) Distributions and population structures of two intertidal estuarine polychaetes in the lower St. Lawrence Estuary, with special reference to environmental factors. Mar Biol 105:297-306

Miron G, Desrosiers G, Retiere C, Lambert R (1991a) Dispersion and prospecting behaviour of the polychaete Nereis virens (Sars) as a function of density. J Exp Mar Biol Ecol 145:65-77

Miron G, Desrosiers G, Retière C, Lambert R (1991b) Spatiotemporal evolution of tunnel systems formed by the polychaete Nereis virens (Sars) with respect to population density. Rev Can Zool 69:39-42

Miron G, Desrosiers C, Retière C (1992a) Organisation of fighting in the polychaete Nereis virens (Sars) and the effects of residency and orientation. Behaviour 121:20-34

Miron G, Desrosiers G, Retière C, Masson S (1992b) Variations in time budget of the polychaete Nereis virens as a function of density and acclimation after introduction to a new burrow. Mar Biol 114:41-48

Olive PJW (1977) The life history and population structure of the polychaetes Nephtys ceaca and Nephtys hombergi with special reference to the growth rings in the teeth. J Mar Biol Assoc UK 57:133-150

Olive PJW (1992) The adaptive significance of seasonal reproduction in marine invertebrates - the importance of distinguishing between models. Invertebr Reprod Dev 22: 165-174

Olive PJW, Morgan PJ (1983) A survey of the age structure of beach populations of Nephtys species in the British Isles: the basis of population fluctuations. Oceanol Acta 141-145

Olive PJW, Rees SW, Djunaedi A (1998) The influence of photoperiod and temperature on oocyte growth in the semelparous polychaete Nereis (Neanthes) virens Sars. Mar Ecol Prog Ser 172:169-183

Olive PJW, Lewis C, Beardall V (2000) Fitness components of seasonal reproduction: an analysis using Nereis virens as a life history model. Oceanol Acta 23:377-389

Olive PJW, Lewis C, Beardall V, Last KS, Bentley MG (2001) Fitness consequences of seasonal reproduction: experiments on the polychaete Nereis virens Sars. In: Atkinson D, Thorndyke M (eds) Environment and animal development: genes, life histories and plasticity. BIOS Scientific Publishers, Oxford, p 321-341 
Orton JH (1920) Sea temperature, breeding and distribution in marine animals. J Mar Biol Assoc UK 12:336-339

Rees SW, Olive PJW (1999) Photoperiodic changes influence the incorporation of vitellin yolk proteins by oocytes of the semelparous polychaete Nereis vivens (Sars). Comp Biochem Physiol A-Mol Integr Physiol 123(2):213-220

Rees SW, Olive PJW (2000) Manipulating the timing of maturation and competence for fertilization and development of oocytes from the semelparous polychaete Nereis (Neanthes) virens Sars. Invertebrate Reprod Dev 38:81-84

Reise K, Gollasch S, Wolff WJ (1999) Introduced marine species of the North Sea coasts. Helgol Meeresunters 52: 219-234

Schoener TW (1983) Field experiments on inter-specific competition. Am Nat 122:240-285

Editorial responsibility: Otto Kinne (Editor),

Oldendorf/Luhe, Germany
Smith CR, Present TMC (1983) In vivo marking of shallow water and deep-sea amphipods by ingestion of bait mixed with fast green. Mar Biol 73:183-192

Snow DR, Marsden JR (1974) Life cycle, weight and possible distribution in a population of Nereis virens from New Brunswick. J Nat Hist 8:513-527

Thorson G (1950) Reproduction and larval ecology of marine bottom invertebrates. Biol Rev 25:1-45

Underwood AJ (2000) Experimental ecology of rocky intertidal habitats: what are we learning? J Exp Mar Biol Ecol 250:51-76

Watson GJ, Williams ME, Bentley MG (2000) Can synchronous spawning be predicted from environmental parameters? A case study of the lugworm Arenicola marina. Mar Biol 136:1003-1017

Submitted: August 16, 2002; Accepted: February 14, 2003 Proofs received from author(s): May 15, 2003 